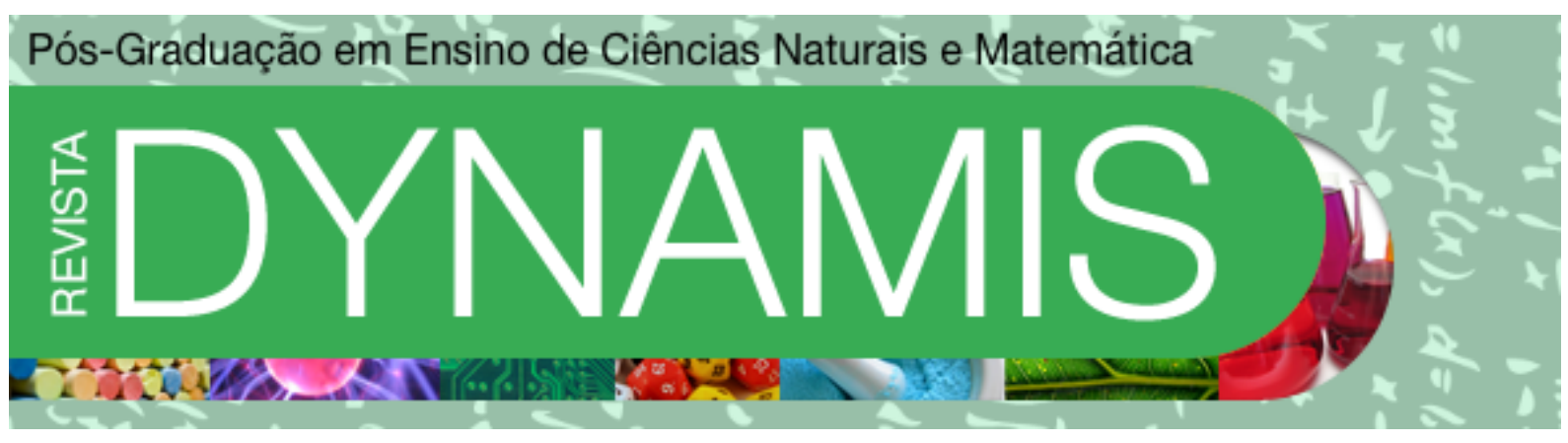

\title{
CONSTRUÇÃO DE UM INSTRUMENTO PARA IDENTIFICAÇÃO DE BARREIRAS EXISTENTES NO USO DA TECNOLOGIA DA INFORMAÇÃO E COMUNICAÇÃO NA PRÁTICA DOCENTE
}

Identification of Existing Barriers in the Use of Information Technology and Communication in Practice Teaching - Course Methodology

Vera Rejane Niedersberg Schuhmacher

PPGECT - Programa de Pós-Graduação em Educação Científica e Tecnológica

Universidade Federal de Santa Catarina - UFSC

vera.schuhmacher@gmail.com

José de Pinho Alves Filho

PPGECT - Programa de Pós-Graduação em Educação Científica e Tecnológica

Universidade Federal de Santa Catarina - UFSC

jopinhofilho@gmail.com 


\section{Resumo}

A Tecnologia da Informação e Comunicação - TIC vem sendo apresentada como um novo domínio da ciência, seu intercambio entre diferentes saberes propicia possibilidades reais para o Ensino se concebida na integração curricular nas práticas em sala de aula. Os professores reconhecem o valor da TIC na educação, mas experimentam dificuldades com o processo de adoção dessas tecnologias, é uma minoria que faz uso no processo de ensino-aprendizagem. O objetivo desta investigação é relatar e classificar o aparecimento de barreiras existentes, quando da inserção das TIC no Ensino de Ciências. A hipótese desta pesquisa é que barreiras percebidas no processo de integração da TIC em sala de aula possam ser interpretadas a partir dos obstáculos epistemológicos percebidos por Bachelard e obstáculos didáticos de Brousseau. Acredita-se que se conhecendo a gênese dos obstáculos, que frustram e impedem o uso da TIC na prática docente, será possível a definição de estratégias de compreensão e superação destes obstáculos. Neste artigo é apresentado o referencial teórico e a metodologia de desenvolvimento da investigação que procura dar respostas as hipóteses propostas na pesquisa.

Palavras-chave: Tecnologia da Informação e Comunicação; Obstáculos Epistemológicos; Obstáculos Didáticos; Ensino de Ciências.

\section{Abstract}

The Information and Communication Technology - ICT has been presented as a new field of Science, their exchange between different knowledge provides real possibilities for schools is designed to integrate curricular practices in the classroom. Teachers recognize the value of ICT in education, but experience difficulties with the process of adoption of these technologies, it is a minority that makes use in the teaching-learning process. The goal of this research is to describe and classify the appearance of barriers, upon insertion of ICT in science education. My hypothesis is that perceived barriers in the process of integration of ICT in the classroom can be interpreted from the epistemological obstacles perceived by Bachelard and didactic obstacle perceived by Brousseau. It is believed that to know the genesis of the obstacles that frustrate and to prevent the use of ICT in teaching practice will be possible to define strategies for understanding and overcoming these obstacles. This article gives an account of the theoretical and methodological approach for developing research that attempts to cover the proposed research hypotheses.

Keywods: Information and Communication Technology; Epistemological Obstacles, Educational Obstacles, Science Teaching. 


\section{A Tecnologia da Informação e Comunicação}

Os recursos oferecidos pela TIC são identificados na literatura como novas tecnologias, ou ainda inovações tecnológicas. Miranda (2007, p.42) define a TIC como "a conjugação da tecnologia computacional ou informática com a tecnologia das telecomunicações". A TIC vem atendendo, por meio de seus variados recursos, os mais diversos segmentos da vida humana proporcionando rapidez e comodidade na execução de tarefas em setores como a indústria, o comércio, o entretenimento e o Ensino. A promoção da TIC no Ensino é vista como uma forma de contribuir com o acesso universal à Educação e a melhoria da qualidade do ensino-aprendizagem. Sua inserção abre novas áreas de conhecimento como a tecnologia educacional, que percebe a tecnologia sujeita aos objetivos educacionais, assim a busca que se tem é o uso adequado dos recursos tecnológicos no apoio ao processo de ensinoaprendizagem.

Entretanto o uso das novas tecnologias divulgada como uma promessa no Ensino deixa atualmente poucos traços na realidade educacional. Entre os professores é uma minoria que faz uso da TIC no processo de ensino-aprendizagem em suas aulas (BALANSKAT ET AL, 2006).

As políticas governamentais partiram da premissa de que a oferta de TIC nas escolas seria por si só suficiente para que a mesma fosse incorporada ao dia a dia do Ensino escolar. Contrapondo esta premissa governamental, Lévy (1996) faz uma reflexão sobre a informatização somente da escola, afirmando estar destinada ao fracasso toda e qualquer análise de informatização fundada sobre uma pretensa essência dos computadores. O esforço em equipar as escolas, é realmente imprescindível para que se tenham condições de implementar um processo de ensino onde ocorra a integração curricular da TIC. Mas é simplista a ideia de que esta integração da TIC dependa apenas de recursos de software e hardware sem que neste cenário se pense nos atores principais do processo: o aluno e o professor.

O professor ao fazer uso da TIC é encarregado de uma grande responsabilidade - a de utilizar as TIC como recurso para construir e difundir conhecimentos. Tardif $(2002$, p.31) afirma "[...] ser o professor alguém que sabe alguma coisa e cuja função é transmitir este saber aos outros". Pimenta contribui apontando "[...] ser a atividade do professor ensinar contribuindo assim no processo de humanização do aluno historicamente situado" (PIMENTA, 2002, P.10).

Aos professores são solicitados novos saberes e competências para lidar criticamente com as TIC em seu dia a dia docente. Ao docente é solicitado conhecer o computador, os suportes midiáticos e todas as possibilidades educacionais e interativas das redes e espaços virtuais para aproveitá-las nas mais variadas situações de ensino-aprendizagem e nas mais diferentes realidades educacionais (KENSKI, 2001).

A inserção da TIC na prática em sala de aula vem sendo proposta por diferentes países, inclusive o Brasil, nos últimos 50 anos, mas a leitura em relatos nacionais ${ }^{1} \mathrm{e}$ internacionais ${ }^{2}$ aponta reiteradamente para possíveis barreiras que incrustradas no processo de Ensino dificultam seu uso. Tais barreiras se externalizam em situações que se referem a TIC como a pouca habilidade do professor no uso, a falta de motivação e confiança na utilização, a ausência e a má qualidade da infraestrutura, o acesso limitado a equipamentos e a ausência de integração da TIC nas estratégias escolares entre outras.

\footnotetext{
${ }^{1}$ Machado (2010). Santos et al (2009). Cysneiros et al (2011). Molina et al (2011).

2 Hinostroza et al (2011). Olson et al (2009). Law et al (2008).

48
} 
O ponto de partida desta investigação é dado por questões norteadoras: Quais as barreiras enfrentadas pelo docente na inserção da TIC em sua prática docente?

Neste sentido, torna-se necessário investigar se os saberes mobilizados, durante a formação permitem ao futuro professor, legitimar os saberes necessários à sua profíssão de forma apropriada sobre as TIC. Sob este aspecto, no Brasil, a TIC é usada na prática docente? Como é explorada? E, qual a sua importância?

Os currículos existentes para a formação de professores no Ensino de Ciências ${ }^{3}$ abordam o uso da TIC? Se abordam de que modo essa preparação vem ocorrendo? Como ocorre a inserção deste conhecimento nas disciplinas? As disciplinas desenvolvem as habilidades e saberes necessários, para uma preparação adequada dos futuros professores, para o uso da TIC?

Frente às questões anteriores tem-se por objetivo da pesquisa relatar e classificar a manifestação de barreiras existentes quando da inserção das tecnologias de informação e comunicação no Ensino.

A hipótese é que barreiras percebidas no processo de integração da TIC em sala de aula configuram-se além de carências como infraestrutura e que possam ser interpretadas a partir dos obstáculos epistemológicos percebidos por Bachelard e dos obstáculos didáticos de Brousseau.

Acredita-se que conhecer a gênese dos obstáculos, que frustram e até impedem o uso da TIC na prática docente, permitirá o apoio e a definição de estratégias de compreensão e superação dos obstáculos por parte de gestores, pesquisadores, formadores e professores. Este artigo traz o relato da construção do referencial teórico e a metodologia de desenvolvimento da investigação, a qual procura dar respostas às hipóteses propostas na pesquisa.

\section{Os Dispositivos Legais e suas Recomendações sobre o Uso da TIC na Educação Básica}

O uso das TICs no Ensino e sua aplicabilidade depende de dispositivos legais federais, estaduais e municipais que fomentem sua promoção e uso. Os saberes da profissão docente são influenciados por diretrizes e leis que orientam ou sugerem o planejamento curricular e conteúdos mínimos. Portanto, cabe refletir que, para que o uso da TIC efetivamente ocorra, é necessário o apoio do governo na forma de resoluções e leis que promovam ou indiquem ser o uso da tecnologia em sala aula, uma definição tomada como base para a educação nacional. São apresentados a seguir alguns destes instrumentos e seu direcionamento a cerca da TIC e seu uso no Ensino.

A Lei de Diretrizes e Bases da Educação Nacional - LDB não apresenta em seu texto direcionamentos sobre o uso da TIC na Educação escolar. Define de forma genérica o uso da tecnologia para o Ensino Fundamental e seu uso não é identificado de forma específica.

$\mathrm{Na}$ leitura dos Parâmetros Curriculares Nacionais - PCN identifica-se a forte recomendação sobre o uso da TIC no ambiente escolar. No texto apresenta-se a preocupação de que seja usada na escola não apenas como um instrumento de ensino-aprendizagem escolar, mas também como um instrumento a ser usado pelo aluno na vida em sociedade.

Nas Diretrizes Curriculares Nacionais para a Educação Básica - DCNEB encontra-se explicitamente serem as TIC, parte de um contínuo desenvolvimento de tecnologias que

\footnotetext{
${ }^{3}$ Ensino de Ciências a ser entendido no texto como as Licenciaturas em Física, Química, Matemática e Biologia.
} 
devem apoiar e enriquecer o processo de ensino-aprendizagem. Sugere-se seu uso de forma adaptada para servir a fins educacionais e como tecnologia assistiva, possibilitando a interatividade virtual. As diretrizes indicam a necessidade da inserção curricular da TIC de forma que esta perpasse transversalmente a proposta curricular, desde a Educação Infantil até o Ensino Médio, imprimindo direção aos projetos político-pedagógicos.

Em leituras realizadas para a fundamentação teórica desta pesquisa, observou-se que as obstruções no processo de integração da TIC se configuravam além dos aspectos físicos e estruturais inerentes da instalação e dos próprios recursos computacionais oferecidos às escolas. Especula-se também que as atitudes do docente, que remetem para sentimentos como a insegurança, a resistência entre outros, no uso da TIC tenha sua gênese no ato de conhecer este objeto.

A inserção da TIC na prática docente e sua pouca eficácia no sistema de Ensino parecem estar relacionadas a dificuldades que sombreiam este conhecimento o que nos remete a uma leitura acerca de origem de barreiras ou obstáculos epistemológicos segundo a definição de Bachelard e dos obstáculos didáticos referenciados por Brousseau.

\section{O Obstáculo Epistemológico}

O obstáculo epistemológico pode ser entendido como qualquer conceito ou método que impede a ruptura epistemológica. Para Bachelard, a noção do obstáculo epistemológico permite tratar do caráter insistente e por vezes generalizado de certas resistências à apropriação do conhecimento científico.

“... é no âmago do próprio ato de conhecer que aparecem os obstáculos, por uma espécie de imperativo funcional, lentidões e conflitos" (BACHELARD, 1938, p.17).

Dentre os obstáculos apontados por Bachelard tem-se que o obstáculo generalista e o da experiência primeira, são os considerados relevantes na estrutura deste trabalho.

A ruptura, por sua vez, sugere que há uma barreira que deve ser destruída e por fim superada para que seja possível o progresso científico. Os obstáculos epistemológicos geram a estagnação, a inércia e, por vezes, a própria regressão ao invés do progresso das ciências.

Ao nos confrontarmos com o obstáculo epistemológico generalista observa-se que o conhecimento do fenômeno geral é usado para tudo compreender. A partir daí têm-se generalidades por ora mal colocadas, com as quais, se perdem as ligações essenciais do fenômeno. Os questionamentos são resolvidos com respostas genéricas, vagas, adaptando o geral ao específico.

O obstáculo epistemológico da experiência primeira, colocado antes e acima da crítica, é representado pelos conhecimentos primeiros que não foram filtrados pela razão, pois foram aceitos de forma imediata. Assim, "[...] o que existe de mais imediato na experiência primeira somos nós mesmos, nossas surdas paixões, nossos desejos inconscientes" (Bachelard, 2001, p.57).

Ao categorizar os obstáculos epistemológicos que obstruem o progresso científico, Bachelard faz uma incursão nas questões educacionais introduzindo a conceituação do obstáculo pedagógico. Estes constituem um obstáculo à apropriação do conhecimento do aluno, obstáculos que os professores enfrentam no cotidiano da sua prática docente, sendo manifestados por conflitos e barreiras que dificultam o processo de ensinar e aprender. 
De outro lado o professor estabelece um obstáculo didático ao ignorar que as crianças chegam às escolas com conhecimentos pré-estabelecidos sobre computadores, internet, celulares que lhe foram apresentados de uma forma atraente e duradoura, pela onda de consumo tecnológico. A criança traz consigo o conhecimento em TIC adquirido em seu dia a dia.

Consideramos nesta pesquisa que as dificuldades citadas em relação ao uso da TIC podem se configurar como obstáculos epistemológicos, pois são obstáculos pertencentes à própria natureza do conhecimento sobre as TIC. E consideram-se obstáculos didáticos as dificuldades do docente quando faz uso da TIC no Ensino, pois são os relativos às escolhas feitas no sistema educativo, que estão relacionadas com o cotidiano do professor.

\section{O Obstáculo Didático}

Brousseau analisa o obstáculo, como um meio de interpretar alguns dos erros recorrentes e não aleatórios cometidos pelos estudantes (BROUSSEAU, 1976). O erro não deve ser visto como o efeito da ignorância, da incerteza ou do acaso, mas sim, o efeito de um conhecimento anterior. Brousseau classifica os obstáculos em: obstáculos de origem ontogênica, de ordem didática, de ordem epistemológica e de ordem cultural. Obstáculos didáticos de origem ontogênica "são aqueles que ocorrem a partir das limitações (incluindo neurofisiológica) do sujeito em um momento de seu desenvolvimento: ele desenvolve o conhecimento de forma apropriado os seus meios e objetivos" (BROUSSEAU, 1976, p.108).

Obstáculos de ordem didática são aqueles que parecem por meio de estratégias de ensino, formando-se por um erro na aprendizagem ou por uma aprendizagem incompleta. São de origem epistemológica e não podem, nem devem escapar ao próprio fato de seu papel constitutivo do conhecimento.

Obstáculos didáticos de origem cultural se apresentam a partir de situações nas quais, o professor reage a situações de Ensino fazendo uso de suas crenças, de respostas do senso comum, simplistas, baseadas em experiências não científicas.

Brousseau (1976) sugere que a gênese de um obstáculo didático ocorre a partir da escolha de estratégias de Ensino que deflagram conhecimentos incompletos ou incorretos e que ao longo do tempo tornam-se obstáculos para o desenvolvimento de um conceito.

Entendemos que, para suplantar os obstáculos didáticos envoltos no uso da TIC, são necessárias, ações que busquem superar os obstáculos, que estão sob a responsabilidade dos professores.

\section{Construção dos Instrumentos da Pesquisa}

O percurso metodológico adotado na pesquisa e descrito neste artigo, têm por objetivo investigar as barreiras que se manifestam na prática docente dos professores, do Ensino Médio em disciplinas de Física, Matemática, Biologia e Química, quanto ao uso ou não da TIC em suas aulas.

A natureza da pesquisa envolve o tratamento de dados de ordem qualitativa e quantitativa. Os aspectos quantitativos serão tratados por meio da estatística simples pelo qual o procedimento objetiva calcular medidas que caracterizam variáveis contínuas, no que se refere a medidas de tendência central, de dispersão, máximos, mínimos, amplitudes, etc. $\mathrm{Na}$ análise qualitativa dos registros definiu-se o uso da Análise de Conteúdo categorial, a qual Bardin descreve como: 
“.. uma operação de desmembramento do texto em unidades onde é possível identificar os diferentes núcleos de sentido que constituem a comunicação, e posteriormente, realizar o seu reagrupamento em classes ou categorias. A categorização ocorre após a análise do material" (Bardin, 2004, p. 201).

A metodologia de investigação começou a ser construída a partir das primeiras inferências obtidas pela leitura dos relatos nacionais e internacionais. Nos documentos, artigos científicos $^{1}$ e relatórios internacionais ${ }^{2}$, identificamos as barreiras que são enfrentadas pelos docentes as quais se apresentam de forma bastante evidente como: as más condições físicas dos ambientes onde a prática ocorre, a qualidade dos computadores, o apoio técnico para a conservação dos equipamentos e do software ou mesmo do apoio institucional para seu uso.

Mas além destas, que são facilmente identificáveis, foi possível perceber nestes relatos "pistas" sobre as barreiras que poderiam estar obstruindo o uso da TIC pelo docente e que se manifestam não de forma concreta como as citadas anteriormente, mas de forma mais sutil na "forma" de sentimentos como a insegurança, a resistência ao uso, à descrença e a indiferença. $\mathrm{O}$ desenvolvimento do tema de pesquisa foi estabelecido a partir de duas etapas. A primeira etapa da investigação se debruça sobre a hipótese: Barreiras no uso da TIC na prática docente podem ter origem na formação inicial do licenciado?

O Quadro 1 apresenta os questionamentos oriundos da hipótese, os quais deverão de ser respondidos durante a investigação e, por fim, foram delineados as técnicas utilizadas na primeira etapa, o corpus da análise e a ferramenta de análise proposta.

Quadro 1. Primeira Etapa da Investigação

\begin{tabular}{|c|c|c|c|}
\hline \multicolumn{4}{|c|}{$\begin{array}{l}\text { Hipótese: Barreiras no uso da TIC na prática docente podem ter origem na formação inicial do } \\
\text { licenciado? }\end{array}$} \\
\hline \multicolumn{4}{|c|}{$\begin{array}{l}\text { Objetivo: investigar a proposta de inserção do uso da TIC de forma curricular nos Cursos de } \\
\text { Licenciatura. }\end{array}$} \\
\hline Técnica de Pesquisa & Corpus de Análise & Questões de Pesquisa & $\begin{array}{l}\text { Ferramenta } \\
\text { de Análise }\end{array}$ \\
\hline Análise Documental & $\begin{array}{l}\text { Projetos Político } \\
\text { Pedagógicos }\end{array}$ & $\begin{array}{l}\text { - O conhecimento em TIC está } \\
\text { sendo garantido nos cursos de } \\
\text { Licenciatura? }\end{array}$ & \multirow[b]{2}{*}{ 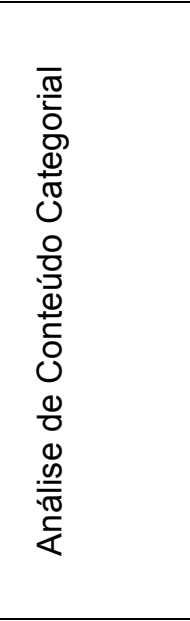 } \\
\hline Entrevista & $\begin{array}{l}\text { Transcrição das } \\
\text { entrevistas dos } \\
\text { Coordenadores } \\
\text { das } \\
\text { Licenciaturas }^{4}\end{array}$ & $\begin{array}{l}\text { - A inserção da TIC curricular foi } \\
\text { apoiada pelo colegiado? } \\
\text { - O uso da TIC na prática docente } \\
\text { está efetivamente ocorrendo na } \\
\text { Licenciatura? } \\
\text { - É oferecida infra estrutura } \\
\text { adequada para a implementação } \\
\text { da TIC na prática docente? } \\
\text { - Qual a intenção do uso da TIC } \\
\text { no curso? } \\
\text { Os docentes da licenciatura são } \\
\text { favoráveis ao uso da TIC? }\end{array}$ & \\
\hline
\end{tabular}

Fonte: Elaborado pela autora

\footnotetext{
${ }^{4}$ Licenciaturas de Física, Química, Matemática, Biologia da Universidade Federal de Santa Catarina e da Universidade Estadual de Santa Catarina
} 
A escolha dos Projetos Político Pedagógico - PPP, como primeiro documento de análise ocorreu, porque estes são documentos norteadores da execução dos cursos, acordado pelos membros da Instituição e assumidos por ela, é presumido que contenham e/ou forneçam indicativos das competências desejadas para o futuro profissional ali formado e que este se aproprie destas ao longo do curso. Desta forma, foi feita a leitura de tais documentos à luz da Análise Documental.

A leitura do projeto se deu em busca de informações que indiquem definições sobre:

a) as habilidade e competências sugeridas no PPP para o futuro licenciado;

b) o perfil do futuro docente envolvendo o conhecimento em TIC;

c) as disciplinas curriculares que envolvam o conhecimento em TIC;

d) as bibliografias que sugiram o uso da TIC na prática docente e que se apresentam na disciplina proposta no PPP;

e) as definições de estruturas físicas que incorporem o uso da TIC para funcionamento do curso.

Para a interpretação dos dados lançou-se mão da Análise de Conteúdo Categorial. Os resultados obtidos na análise trouxeram respostas para algumas questões levantadas, mas também, a inquietação da pesquisadora que considerou a fragilidade dos dados quanto à realidade instaurada na prática nos cursos de licenciatura. Fragilidade aqui exposta, considerando-se a possibilidade do uso da TIC estar ocorrendo como uma ferramenta de mediação em disciplinas de conteúdo específico mesmo não havendo menção desta nas ementas de disciplinas ou ao contrário, estar sendo apontada em ementas de disciplinas, mas não estar inserida na prática diária do docente.

Fazendo uso das palavras de Pinho Alves (1990, p. 142) “... a ementa oficial, de modo geral, não passa de uma relação de títulos correspondentes às unidades do programa da disciplina ou então dos títulos dos capítulos do livro-texto adotado".

Assim, tomou-se como necessário aprofundar as informações obtidas na análise documental tornando os resultados significativos e válidos. Com a preocupação de entender, registrar e analisar os PPP considerou-se compreender a realidade instaurada na prática de formação inicial a partir do conhecimento tácito dos coordenadores de curso, sobre o PPP, tanto do conteúdo, quanto do papel de educador, como das intenções do Curso frente às TIC.

Construiu-se um no instrumento de coleta de registros, desta feita, fazendo uso da entrevista semiestruturada onde o sujeito alvo foram os coordenadores dos cursos identificados no escopo da pesquisa. A entrevista é um instrumento que permite "a captação imediata e corrente da informação desejada, praticamente com qualquer tipo de informante e sobre os mais variados tópicos" (LÜDKE et al, 1986, p.34).

Buscar-se-á o viés dinâmico do curso em funcionamento, com uma atenção a percepção do coordenador quanto aos docentes do quadro e sua motivação para o uso da TIC na prática docente. Para a construção do protocolo da entrevista foi construída uma matriz dividida em seis etapas (Quadro 2), onde em cada etapa foram identificados os objetivos e o número de questões a serem contempladas. As questões da entrevista foram elencadas a partir dos objetivos pretendidos.

Foram entrevistados sete coordenadores de cursos de licenciatura. $\mathrm{Na}$ análise dos registros foi possível perceber as barreiras que dificultam a inserção das TIC dentro dos cursos de formação inicial. Identificaram-se barreiras estruturais e indicativos que apontam 
para barreiras didáticas e epistemológicas do professor quanto ao uso da TIC na prática docente.

Para responder as perguntas de pesquisa propostas, será necessário investigar qual é a relação dos professores com estas tecnologias em sala de aula refletindo sobre os conceitos e as interpretações dos educadores sobre o uso do computador na educação escolar. Os licenciados são a ponta deste iceberg imerso no dia a dia escolar, sua contribuição na pesquisa deve apontar como acontece o uso da TIC em sua prática ou, caso esta não aconteça, as barreiras e motivadores que o impedem.

Mas por que investigar os professores docentes da licenciatura? Porque se entende como promissor para os resultados da pesquisa investigar qual é o conhecimento do professor formador acerca da TIC, como este vê seu uso no ensino. Sendo este, o responsável pela função de ensinar os futuros professores, há de se considerar que, sua atuação influencie decisivamente na "construção" deste conhecimento e alicerce as crenças do futuro licenciado quanto ao seu uso. Este pensamento é reforçado por Pinho Alves (1990, p.44) que salienta "que o professor, por sua vez, transmitirá a seus alunos os mesmos valores, práticas escolares e conhecimento formal que lhe foi transmitido durante o período de formação".

Quadro 2. Matriz - Entrevista Coordenadores Licenciatura

\begin{tabular}{|c|c|c|}
\hline Etapa & Objetivos & $\begin{array}{c}N^{0} \text { de } \\
\text { Questões }\end{array}$ \\
\hline $\begin{array}{l}\text { IDENTIFICAÇÃO DO } \\
\text { ENTREVISTADO }\end{array}$ & $\begin{array}{l}\text { Identificar o sujeito da pesquisa quanto a } \\
\text { responsabilidade junto ao curso e formação. }\end{array}$ & 3 \\
\hline $\begin{array}{l}\text { A INTENÇÃO DO USO } \\
\text { DA TIC NO CURSO - O } \\
\text { PROJETO PEDAGÓGICO } \\
\text { DO CURSO }\end{array}$ & $\begin{array}{l}\text { Investigar a existência de disciplinas que contemplam o } \\
\text { conhecimento em TIC e que estejam inseridas no currículo } \\
\text { do curso. Investigar a percepção sobre o sentimento } \\
\text { existente quanto a inserção da TIC de forma curricular por } \\
\text { parte dos elaboradores do projeto. }\end{array}$ & 4 \\
\hline $\begin{array}{c}\text { A INTENÇÃO DO USO } \\
\text { DA TIC NO CURSO - O } \\
\text { OLHAR } \\
\text { DIDÁTICO/PEDAGÓGICO }\end{array}$ & $\begin{array}{l}\text { Investigar a existência de apoio didático e pedagógico ao } \\
\text { docente quanto do uso da TIC em suas práticas educacionais }\end{array}$ & 3 \\
\hline $\begin{array}{l}\text { APOIO NO USO DA TIC } \\
\text { EM SALA DE AULA }\end{array}$ & $\begin{array}{l}\text { Investigar a estrutura física, a estrutura de software, o } \\
\text { suporte técnico o apoio didático-pedagógico oferecido pela } \\
\text { Instituição à alunos e docentes. }\end{array}$ & 4 \\
\hline $\begin{array}{l}\text { A TIC NAS DISCIPLINAS } \\
\text { DO CURSO }\end{array}$ & Investigar qual a intenção de uso da TIC no curso. & 6 \\
\hline $\begin{array}{l}\text { PERCEPÇÃO DO } \\
\text { COORDENADOR }\end{array}$ & $\begin{array}{l}\text { Investigar a percepção do coordenador quanto ao grupo de } \\
\text { professores e seus sentimentos quanto ao uso da TIC na } \\
\text { prática docente. }\end{array}$ & 4 \\
\hline
\end{tabular}

Fonte: Elaborado pela autora

O Quadro 3 apresenta os questionamentos oriundos da hipótese, os quais deverão de ser respondidos durante a investigação, as técnicas utilizadas na segunda etapa, o corpus da análise, questões de pesquisa e a ferramenta de análise proposta. 
Quadro 3. Segunda Etapa da Investigação

Hipótese: É possivel identificar obstáculos epistemológicos, definidos por Bachelard ou obstáculos didáticos definidos por Brousseau, no uso da TIC na prática docente?

Objetivo: investigar a proposta de inserção do uso da TIC de forma curricular nos Cursos de Licenciatura.

\begin{tabular}{|c|c|c|c|}
\hline Técnica de Pesquisa & Corpus de Análise & Questões de Pesquisa & $\begin{array}{c}\text { Ferramenta } \\
\text { de Análise }\end{array}$ \\
\hline \multirow[t]{2}{*}{ Questionário } & $\begin{array}{l}\text { Respostas } \\
\text { Professores } \\
\text { Ensino Médio }\end{array}$ & \multirow{2}{*}{$\begin{array}{l}\text { - Qual a origem do conhecimento } \\
\text { em TIC que o docente possui e } \\
\text { sua habilidade em usá-la na } \\
\text { prática docente? } \\
\text { - O docente faz uso da TIC em } \\
\text { sua prática docente? Qual o } \\
\text { objetivo deste uso? } \\
\text { - Quais as barreiras enfrentadas } \\
\text { pelo docente no uso da TIC? } \\
\text { Quais são os motivadores que } \\
\text { levam o docente a fazer uso da } \\
\text { TIC em sala de aula? }\end{array}$} & \multirow{2}{*}{ 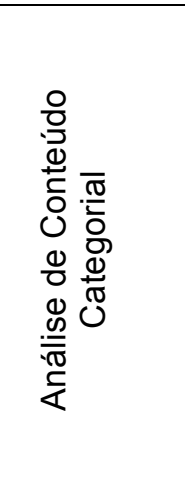 } \\
\hline & $\begin{array}{lr}\text { Respostas } & \\
\text { Professores } & \text { dos } \\
\text { Cursos } & \text { de } \\
\text { Licenciatura }^{4} & \end{array}$ & & \\
\hline
\end{tabular}

Fonte: Elaborado pela autora

Construiu-se dois questionários que mesclam questões abertas e fechadas, para obter dados satisfatórios às questões e objetivos propostos na pesquisa:

a) o instrumento "Questionário - Docentes do Ensino Médio" foi aplicado com docentes do Ensino Médio da Gerência de Educação de Blumenau;

b) o instrumento "Questionário - Docente Licenciatura" foi aplicada com docentes dos cursos de licenciatura cujos projetos pedagógicos foram corpus da análise documental.

A coleta de registros foi feita com professores do Ensino Médio da Gerência de Educação de Blumenau para os docentes das disciplinas de Física, Química, Matemática e Biologia. Na coleta do questionário para docentes de licenciatura a amostra foi realizada com professores de Licenciatura.

Para a construção dos questionários, foi elaborado um quadro matriz. Neste quadro foram listadas as dimensões, em número de cinco, da pesquisa elencadas a partir dos objetivos e finalidades do questionário. Bardin (2004) comenta serem as dimensões de análise amplas, pois contém elementos que são analisados sob diferentes critérios e perspectivas. Para cada dimensão de pesquisa foram apontados os respectivos objetivos, para cada objetivo um determinado número de questões foi inserida no questionário para dar conta de alcançar o objetivo proposto.

Cabe salientar serem as dimensões as mesmas para ambos os protocolos, variando apenas objetivos e o número de questões para algumas das dimensões pelas questões que se pretendem responder para cada grupo de entrevistados (Quadro 4). 
Quadro 4. Matriz de dimensões e Objetivos - Docentes Ensino Médio/ Docentes Licenciatura

\begin{tabular}{|c|c|c|}
\hline Dimensões & Objetivos & $\begin{array}{c}\text { № de } \\
\text { Questões }\end{array}$ \\
\hline \multirow{5}{*}{$\begin{array}{c}\text { PARTE I } \\
\text { CONHECIMENTO } \\
\text { DOCENTE EM TIC }\end{array}$} & Conhecer o tempo que o docente faz uso da TIC no ensino. & 1 \\
\hline & $\begin{array}{l}\text { Conhecer o ambiente onde o docente tem acesso ao uso do } \\
\text { computador. }\end{array}$ & 1 \\
\hline & $\begin{array}{l}\text { Identificar a origem dos conhecimentos de TIC que o docente pos- } \\
\text { sui. }\end{array}$ & 3 \\
\hline & Averiguar a habilidade que o docente possui para fazer uso da TIC. & 1 \\
\hline & $\begin{array}{l}\text { Averiguar a importância dada pelo docente para atividades de for- } \\
\text { mação com foco em TIC. }\end{array}$ & 1 \\
\hline \multirow{3}{*}{$\begin{array}{c}\text { PARTE II } \\
\text { A TIC NA PRÁTICA } \\
\text { DOCENTE }\end{array}$} & Identificar a frequência de uso da TIC na prática docente. & 5 \\
\hline & Identificar o tipo de uso dado a TIC pelo docente em sua prática. & 5 \\
\hline & $\begin{array}{l}\text { Averiguar práticas onde o docente faz uso da TIC como recurso } \\
\text { de mediação. }\end{array}$ & 1 \\
\hline \multirow{2}{*}{$\begin{array}{c}\text { PARTE III } \\
\text { OS OBSTÁCULOS } \\
\text { NO USO DA TIC EM } \\
\text { SALA DE AULA }\end{array}$} & $\begin{array}{l}\text { Investigar as possíveis barreiras que impedem a adesão de } \\
\text { professores no uso da TIC. }\end{array}$ & 5 \\
\hline & $\begin{array}{l}\text { Averiguar o sentimento docente sobre o uso da TIC na prática } \\
\text { docente. }\end{array}$ & 2 \\
\hline \multirow{2}{*}{$\begin{array}{c}\text { PARTE IV } \\
\text { MOTIVAÇÃO PARA } \\
\text { O USO DA TIC NA } \\
\text { PRÁTICA DOCENTE }\end{array}$} & Verificar quais as potencialidades do uso da TIC em sala de aula. & 1 \\
\hline & Conhecer as motivações que o levaram a fazer uso da TIC. & 1 \\
\hline \multirow{3}{*}{$\begin{array}{c}\text { PARTE V } \\
\text { IDENTIFICAÇÃO } \\
\text { DO ENTREVISTADO }\end{array}$} & Conhecer a formação do docente. & 1 \\
\hline & Conhecer o tempo de atuação do docente no magistério. & 1 \\
\hline & Conhecer a atuação profissional do professor no ensino. & 3 \\
\hline
\end{tabular}

Fonte: Elaborado pela autora

\subsection{Dimensões de Análise da Pesquisa para os PPP}

Para a análise categorial dos PPP foi construída a dimensão de pesquisa "Inserção Curricular da TIC" que identificam os elementos a serem analisadas.

A dimensão de análise diferentemente de categoria, em que a exclusão mútua determina que cada elemento não pode ter dois ou mais aspectos passíveis de serem classificados em duas ou mais categorias, são mais amplas e contém elementos que são analisados sob diferentes critérios e perspectivas (BARDIN, 2004).

O foco da análise da dimensão "Inserção Curricular da TIC" está contextualizado na pretensão exposta nos PPP sobre o conhecimento em TIC que, deveria de ser adquirido pelo licenciado no transcorrer do curso de formação inicial. Assim foram definidas a seguintes categorias:

a) competências do licenciado - compreende as competências no que se refere às TIC, que o projeto pedagógico sugere serem adquiridas pelo licenciado durante o curso na forma de objetivos, habilidades, competências e perfil desejado;

b) os obstáculos no uso da TIC - referem-se aos obstáculos estruturais e organizacionais perceptíveis no projeto pedagógico quando da inserção curricular;

c) TIC curricular - as disciplinas inseridas no currículo que envolvem o conhecimento em TIC. Nesta proposta, procura-se preencher a lacuna existente da visão da tecnologia educacional (TIC), veiculada na formação docente incorporando três subcategorias, sendo elas:

a. ferramenta de produção - A TIC proposta no currículo como o ensino da informática ou da inclusão digital do aluno. A proposta curricular é o ensino de 
aplicativos de processamento dos dados para produção ou organização das aulas do professor;

b. mediação didática - A TIC sendo usada como um recurso de mediação pedagógica e aprendizagem dos alunos em disciplinas do currículo;

c. TIC no ensino - A TIC inserida no currículo em disciplinas onde se propõe o ensino de práticas educacionais que incorporam o uso pedagógico da TIC e a TIC vista como objeto de ensino.

A interpretação destes dados, somada ao que a leitura e interpretação dos relatos nacionais e internacionais e as possíveis correlações com as obras de Bachelard e Brousseau, levaram a reflexão e construção das dimensões e categorias que serviriam para a análise dos demais instrumentos de coleta.

\subsection{Dimensões de Análise da Pesquisa para a Entrevista e Questionários}

Para a análise dos registros coletados nos instrumentos de coleta Entrevista e Questionários foram construídas dimensões de análise a partir de um viés único. Assim, teremos as vozes dos diferentes atores da investigação sendo tratadas e interpretadas pela mesma grade de análise.

Foram construídas 5 dimensões de análise de pesquisa sob as quais se encontram as categorias de análise propostas pela pesquisadora:

a) o conhecimento em TIC - compreende o conhecimento que o docente possui em TIC e a origem deste. Nesta dimensão, listam-se as categorias: perfil e competências;

b) obstáculos no uso da TIC - os obstáculos relatados pelos docentes que permeiam o uso da TIC em sua prática em sala de aula. Nesta dimensão, listam-se as categorias obstáculos epistemológicos (experiência primeira, generalização), didáticos (epistemológico, didático) e estruturais (gestão, físicos, software, equipes de apoio);

c) a TIC na prática docente - as disciplinas inseridas no currículo que envolvem as TIC. Compreende as subcategorias mediação didática, ferramenta de produção e TIC no ensino;

d) motivação docente no uso da TIC - os motivos que levam o docente a acreditar ou desacreditar no uso e na potencialidade da TIC no processo ensino-aprendizagem para o aluno. Nesta dimensão, listam-se as categorias potencialidades da TIC e motivação docente;

e) perfil docente - identificação acadêmica profissional do docente, onde se listam as categorias formação e atuação profissional.

A matriz construída (Quadro 5) para a criação do protocolo de entrevistas faz o entrelaçamento de suas questões com os questionários propostos para a investigação com docentes de licenciatura e docentes do ensino médio. 
Quadro 5. Matriz de dimensões - Docentes Ensino Médio/ Docentes Licenciatura

\begin{tabular}{|c|c|}
\hline $\begin{array}{c}\text { Dimensões dos Questionários } \\
\text { Docente Licenciatura / Docentes } \\
\text { Ensino Médio }\end{array}$ & Etapas Matriz Entrevista \\
\hline $\begin{array}{c}\text { CONHECIMENTO DOCENTE EM } \\
\text { TIC }\end{array}$ & $\begin{array}{c}\text { A Intenção do uso da TIC no curso - o } \\
\text { Projeto Pedagógico do Curso }\end{array}$ \\
\hline A TIC NA PRÁTICA DOCENTE & A TIC nas Disciplinas do Curso \\
\hline $\begin{array}{c}\text { OS OBSTÁCULOS NO USO DA TIC } \\
\text { EM SALA DE AULA }\end{array}$ & $\begin{array}{c}\text { Apoio no Uso da TIC em sala de aula } \\
\text { A Intenção do uso da TIC no curso - o } \\
\text { Projeto Pedagógico do Curso }\end{array}$ \\
\hline $\begin{array}{c}\text { MOTIVAÇÃO PARA O USO DA TIC } \\
\text { NA PRÁTICA DOCENTE }\end{array}$ & $\begin{array}{c}\text { Percepção do Coordenador } \\
\text { A Intenção do uso da TIC no curso - o } \\
\text { Projeto Pedagógico do Curso }\end{array}$ \\
\hline $\begin{array}{c}\text { IDENTIFICAÇÃO DO } \\
\text { ENTREVISTADO }\end{array}$ & \begin{tabular}{c} 
Identificação do Entrevistado \\
\hline
\end{tabular} \\
\hline
\end{tabular}

Fonte: Elaborado pela autora

Para ilustrar este entrelaçamento e seus possíveis resultados quanto aos registros da análise, apresentamos uma breve aproximação de algumas questões entre os instrumentos e suas respostas no Quadro 6.

A triangulação entre os instrumentos permite vislumbrar a abrangência dos resultados e sua consistência nos diferentes instrumentos.

Quadro 6. Relacionamento entre Entrevista Coordenador X Questionários Ensino Médio

\begin{tabular}{|c|c|c|}
\hline Entrevista (ENTC) $^{5}$ & Questionário (QPEM) $^{6}$ & Respostas \\
\hline $\begin{array}{l}\text { Parte } 5-A \text { TIC nas } \\
\text { Disciplinas do Curso } \\
\text { Objetivo: investigar qual } \\
\text { a intenção de uso da TIC } \\
\text { no curso e como é } \\
\text { apresentada nas } \\
\text { disciplinas do curso. }\end{array}$ & $\begin{array}{l}\text { Parte I - Habilidade } \\
\text { Docente no uso da TIC } \\
\text { 4. Os conhecimentos que } \\
\text { você possui para lidar } \\
\text { com TIC foram } \\
\text { adquiridos? } \\
\text { 5. Em sua formação } \\
\text { inicial, qual o foco das } \\
\text { disciplinas que } \\
\text { envolviam o uso da TIC? }\end{array}$ & $\begin{array}{l}\text { Como adquiriu o conhecimento em TIC: } \\
\text { ENTC - } 100 \% \text { de forma auto didata } \\
\text { QPEM - } 42,86 \% \text { de forma autodidata; } 28,57 \text { em } \\
\text { cursos de informática; } 0 \% \text { nos cursos de } \\
\text { formação inicial. } \\
\text { Foco dado a TIC no currículo da } \\
\text { Licenciatura: } \\
\text { ENTC - o currículo não apresenta disciplinas de } \\
\text { produção, o uso como mediação didática é fruto } \\
\text { de iniciativas individuais; a TIC como ferramenta } \\
\text { de ensino não está explícita em ementas de } \\
\text { disciplinas. } \\
\text { QPEM - 42.85\% dos professores não teve o } \\
\text { conhecimento em TIC no curso de licenciatura; } \\
28.57 \% \text { tiveram o conhecimento como } \\
\text { ferramenta de produção; } 14.28 \% \text { como } \\
\text { ferramenta de ensino. } \\
48 \% \text { dos professores consideram que sua } \\
\text { formação inicial não foi adequada quanto a }\end{array}$ \\
\hline
\end{tabular}

\footnotetext{
${ }^{5}$ ENTC - Resposta entrevista coordenador.

${ }^{6}$ QPEM - Respostas Questionário Professores Ensino Médio 


\begin{tabular}{|c|c|c|}
\hline & & $\begin{array}{l}\text { inserção da TIC na prática docente o que lhe } \\
\text { causa desconforto quando inquerido sobre seu } \\
\text { uso. }\end{array}$ \\
\hline $\begin{array}{l}\text { Parte } 4 \text { - Apoio no Uso } \\
\text { da TIC em sala de aula } \\
\text { Objetivo: investigar a } \\
\text { estrutura física, a } \\
\text { estrutura de software, o } \\
\text { suporte técnico o apoio } \\
\text { didático-pedagógico } \\
\text { oferecido pela } \\
\text { Instituição à alunos e } \\
\text { docentes. }\end{array}$ & $\begin{array}{l}\text { Parte III - Os obstáculos } \\
\text { no uso da TIC em sala } \\
\text { de aula } \\
\text { 1. Dos obstáculos listados } \\
\text { a seguir, que poderiam } \\
\text { atrapalhar ou impedir o } \\
\text { uso da TIC em sua } \\
\text { prática em sala de aula, } \\
\text { assinale a relevância de } \\
\text { cada um deles } \\
\text { [ESTRUTURA FÍSICA, } \\
\text { SOFTWARE, ÁEOIO } \\
\text { TÉCNICO, GESTÃO] }\end{array}$ & $\begin{array}{l}\text { Obstáculos no uso da TIC docente [softwarel } \\
\text { apoio técnico]: } \\
\text { ENTC - O curso não possui softwares } \\
\text { específicos para as disciplinas do curso, o que } \\
\text { inibi a proposta de uso deste recurso pelo } \\
\text { docente. } \\
\text { A inexistência de equipe de apoio técnico } \\
\text { pedagógico é considerado um obstáculo pelo } \\
\text { coordenador. } \\
\text { QPEM - Dos professores } 85.7 \% \text { consideram ser } \\
\text { um obstáculo a falta de equipes de apoio } \\
\text { pedagógico para o uso da TIC na escola. } \\
\text { A escola não possuir software adequado para a } \\
\text { proposta da disciplina é visto como um obstáculo } \\
\text { por } 71.5 \% \text { dos professores. }\end{array}$ \\
\hline
\end{tabular}

Fonte: Elaborado pela autora

\section{Conclusão}

Resumindo a execução da proposta metodológica, a etapa de coletas já foi cumprida: foram transcritas as 7 entrevistas com os coordenadores propostos, foi realizada a análise documental dos PPP's, foram coletadas 36 questionários de professores docentes das licenciaturas e 41 questionários de professores do Ensino Médio.

A proposta metodológica desenvolvida, para responder ao objetivo de relatar e classificar a manifestação de barreiras existentes quando da inserção das TIC no Ensino, demonstra-se consistente e robusta. Fato este evidenciado pela composição e entrelaçamento de objetivos e questionamentos que são construídos a partir da base de formação do professor do Ensino Médio:

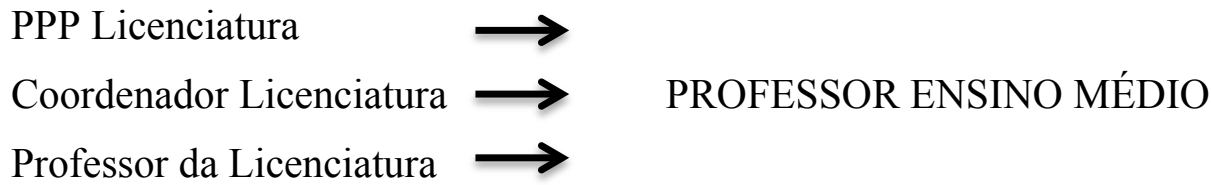

A análise nos PPP's permitiu a compreensão sobre como a TIC foi proposta nas Licenciaturas e sua abrangência como tecnologia educacional no curso. Os demais instrumentos, entrevistas e questionários, evidenciaram qual é a relação dos professores e coordenadores com a TIC em sala de aula, apontando para as barreiras que dificultam ou impedem este processo. A construção do protocolo identificando os objetivos de cada dimensão permitiu uma coleta de registros direcionada e eficiente.

As dimensões de análise propostas permitiram a flexibilidade necessária para a promoção de diferentes visões sobre os registros e a construção das categorias fundamentadas no referencial teórico.

Nos resultados coletados até este momento já é possível perceber que as inquietações sobre o uso da TIC apontam para obstáculos bem mais complexos, a concepção de soluções que equacionam questões de infraestrutura são importantes, mas para que se tenha uma 
adesão concreta em seu uso curricular questões fundamentais devem ser conhecidas para que possam ser superadas.

A soma dos registros e interpretações vem reforçando a hipótese da pesquisadora de que entre barreiras estruturais que impactam o uso da TIC no dia a dia docente também se apresentam obstáculos epistemológicos e didáticos do lado dos professores, sejam universitários ou da educação básica. A formação inicial parece ser um dos pontos nevrálgicos da relação TIC X Professor.

\section{Referências}

BACHELARD, Gaston. (2001). La formation de l'ésprit scientifique. Paris: J. Vrin, 1938. Tradução por Estela dos Santos Abreu. A formação do espírito científico. Rio de Janeiro: Contraponto. 314p.

BALANSKAT, Anja; BLAMIRE, Roger; KEFALA, Stella. (2006). The ICT Impact Report A review of studies of ICT impact on schools in Europe: European Schoolnet in the framework of the European Commission's ICT cluster. Brussels: European Schoolnet. $75 \mathrm{p}$.

BARDIN, Laurence. (2004). L'Analyse de Contenu. Presses Universitaires de France, 1977. Tradução por Luís Antero Reto , Augusto Pinheiro. Análise de conteúdo. São Paulo: Edições 70. 276p.

BROUSSEAU, Guy. (1976). Les obstacles épistémologiques et les problèmes en mathématiques. In: J. Vanhamme \& W. Vanhamme (Eds.), La problématique et l'enseignement des mathématiques. Comptes rendus de la XXVIII e rencontre organisée par la Commission Internationale pour l'Etude et l'Amélioration de l'Enseignement des Mathématiques, Louvain la Neuve. p. 101-117.

CYSNEIROS Paulo G.; CARVALHO Ana B. G.; Panerai Thelma. (2011). O Programa UCA na Visão de Professores Multiplicadores. XXII SBIE - XVII WIE, 12, Aracaju, novembro 2011. Anais do XXII SBIE - XVII WIE . Aracaju. ISSN: 2176-4301

HISNOSTROZA Enrique; LABBÉ Christian; BRUN Mario; MATAMALA Carolina. (2011). Teaching and learning activities in Chilean classrooms: Is ICT making a difference?, Computers \& Education, v. 57, p. 1358-1367.

KENSKI, Vani Moreira. (2001). Em direção a uma ação docente mediada pelas tecnologias Digitais. In: BARRETO, Raquel Goulart (Org.). Tecnologias educacionais e educação a distância: avaliando políticas e práticas. Rio de Janeiro: Quartet. 192p.

LAW, Nancy; PELGRUM, Hans; PLOMP, Tjeerd. (2008). Pedagogy and ICT use in Schools Around the World Findings from the IEA SITES 2006 Study. Comparative Education Research Centre The University of Hong Kong. Hong Kong. 295 p.

LÉVY, Pierri. (1996). Qu'est-ce le virtuel?. Éditions la Découverte. Tradução: Paulo Neves. O que é o Virtual?. São Paulo: Editora 34. 157 p.

LÜDKE, MENGA; ANDRÉ, Marli E. D. A. (1986). Pesquisa em Educação: Abordagens Qualitativas. São Paulo: EPU. 99 p. 
MACHADO, Marco Antonio de Jesus. (2010). Meta Avaliação de Projetos em Educação com o Uso das TIC. 224f. Tese Doutorado (Doutorado em Educação)- Pontifícia Universidade de São Paulo. São Paulo.

MIRANDA, Guilhermina, Lobato. (2007). Limites e Possibilidades das TIC na Educação. Sísifo - Revista de Ciências da Educação, Lisboa, n. 3 , Maio/Agosto de 2007, p. 4150. Acesso em : 10 de outubro de 2012. Disponível em: < http://sisifo.fpce.ul.pt $>$.

MOLINA, Rosane K.; Schlemmer, Eliana. (2011). O uso das tecnologias da Informação e Comunicaçã0 (TIC) em contextos escolares e a melhoria da qualidade da educação. Práxis Educativa, Ponta Grossa, v. 6, nro. 1, p. 91-100.Disponível em: http://www.revistas2.uepg.br/index.php/praxiseducativa/article/viewArticle/1700. Acesso em: Janeiro 2013.

OLSON John F; MARTIN Michael O.; MULLIS Ina V.S (Eds.). (2009). TIMSS 2007 International Database and User Guide. Chestnut Hill, MA: TIMSS \& PIRLS International Study Center, Boston College. ISBN: 1-889938-50-5.

PIMENTA, Selma Garrido (Org). (2002). Saberes pedagógicos e atividade docente. 3a ed. São Paulo: Ed. Cortez. 246p.

PINHO ALVES, José. (1990). Licenciatura em Física da UFSC: Análise à luz do referencial de Eisner e Vallance. 238. Dissertação de Mestrado. CED. UFSC.

SANTOS, Maximiliana B. F.; BORGES, Martha. (2009). Laptops educacionais e o currículo: impressões sobre uma escola piloto do Projeto UCA - Brasil. In: J. Sánchez (Ed.): Nuevas Ideas en Informatica Educativa, Santiago de Chile, v. 5, p. 43-53.

TARDIF, Maurice. (2002). Saberes Docentes e Formação Profissional. Petrópolis, RJ: 2a ed., Ed. Vozes. 325p. 